\title{
Evaluation of Body Condition Score Measured Throughout Lactation as an Indicator of Fertility in Dairy Cattle
}

\author{
G. Banos, ${ }^{1}$ S. Brotherstone, ${ }^{2,3}$ and M. P. Coffey ${ }^{2}$ \\ ${ }^{1}$ Department of Animal Production, School of Veterinary Medicine, \\ Aristotle University of Thessaloniki, GR-54124 Thessaloniki, Greece \\ ${ }^{2}$ Sustainable Livestock Systems, Scottish Agricultural College, \\ Bush Estate, Penicuik, Midlothian, EH26 OPH, United Kingdom \\ ${ }^{3}$ Institute of Cell, Animal and Population Biology, University of Edinburgh, \\ Ashworth Laboratories, King's Buildings, Edinburgh, EH9 3JT, United Kingdom
}

\section{ABSTRACT}

Body condition score (BCS) records of primiparous Holstein cows were analyzed both as a single measure per animal and as repeated measures per sire of cow. The former resulted in a single, average, genetic evaluation for each sire, and the latter resulted in separate genetic evaluations per day of lactation. Repeated measure analysis yielded genetic correlations of less than unity between days of lactation, suggesting that BCS may not be the same trait across lactation. Differences between daily genetic evaluations on d 10 or 30 and subsequent daily evaluations were used to assess BCS change at different stages of lactation. Genetic evaluations for BCS level or change were used to estimate genetic correlations between BCS measures and fertility traits in order to assess the capacity of BCS to predict fertility. Genetic correlation estimates with calving interval and non-return rate were consistently higher for daily BCS than single measure BCS evaluations, but results were not always statistically different. Genetic correlations between BCS change and fertility traits were not significantly different from zero. The product of the accuracy of BCS evaluations with their genetic correlation with the UK fertility index, comprising calving interval and non-return rate, was consistently higher for daily than for single BCS evaluations, by 28 to $53 \%$. This product is associated with the conceptual correlated response in fertility from BCS selection and was highest for early (d 10 to 75) evaluations.

(Key words: body condition score, body condition change, random regression, fertility index)

Abbreviation key: $\mathbf{A C}=$ age at calving, $\mathbf{C I}=$ calving interval, DMY = daily milk yield at test nearest to $\mathrm{d}$ 110, HYS = herd-year-season of visit, HYSd = HYS by day of lactation interaction, $\mathbf{N R}=$ non-return rate $56 \mathrm{~d}$

Received September 24, 2003.

Accepted March 27, 2004.

Corresponding author: G. Banos; e-mail: banos@vet.auth.gr. after the first insemination, $\mathbf{p c h}=$ percentage of North American Holstein genes.

\section{INTRODUCTION}

Long-term selection emphasis on milk yield combined with its antagonistic genetic correlation with female fertility (Pryce et al., 1998; Pryce and Veerkamp, 2001; Roxström et al., 2001) has resulted in a reduced capacity of dairy cows to conceive and carry a calf to term (Royal et al., 2000). Incorporating genetic evaluations for fertility traits into breeding programs (Pryce and Veerkamp, 2001) could help alleviate the problem.

The accuracy of genetic evaluations depends on the number of validated records and the heritability of a trait. In the UK, only about $10 \%$ of milk-recorded herds maintain accurate insemination data (Kadarmideen and Coffey, 2001). Further, the heritability of most fertility traits is quite low, typically $<0.05$ (Wall et al., 2003). Hence, in an environment where the recording of fertility traits is uncertain, indirect measures of fertility must be considered to increase the accuracy of genetic evaluations. Such information may be found in other traits with higher heritability, more readily available records, and considerable genetic correlations with fertility. Milk yield (Harrison et al., 1990; Pryce and Veerkamp, 2001), linear type traits (Pryce et al., 2000), and BCS (Pryce et al., 2000; Dechow et al., 2001; Berry et al., 2003) meet these criteria. Analyzing fertility jointly with milk yield and BCS may also account, to a certain extent, for selection and management bias. Wall et al. (2003) jointly analyzed 4 fertility traits, milk yield, and BCS and produced preliminary fertility evaluations of bulls used in the UK.

Body condition score changes throughout the lactation of a cow, responding to changes in her energy balance (Coffey et al., 2003). As milk yield peaks and demand for energy exceeds intake of energy, the cow mobilizes her lipid reserves and gets thinner, thereby compromising her body condition. This process is related to the daily milk yield curve, which is almost 
exactly opposite to the energy balance and BCS curves (Coffey et al., 2002, 2003). Excessive mobilization of body reserves may have adverse effects on cow fertility and health (Collard et al., 2000; de Vries and Veerkamp, 2000). In fact, inseminations in the UK usually start when daily milk yield approaches its peak, while energy balance and BCS are on the decline. This pattern suggests that BCS at about the time cows are being inseminated might be a more informative fertility predictor than BCS at other stages of lactation. Also, the rate that a cow loses body energy in the beginning of the lactation might be related to her propensity to conceive, although results of Pryce et al. (2001) do not fully support this assertion.

In the UK, field officers of Holstein UK record BCS once for each cow, during their type classification visits to participating herds. First-lactation cows are scored on a scale of 1 to 9 , where $1=$ thin and $9=$ fat. This score is adjusted for recording officer by scaling records so that individual field officer standard deviations are equal to the mean standard deviation of all field officers (Brotherstone, 1994; Jones et al., 1999). Cows are scored only once, each at a different stage of lactation. This single measurement does not capture the BCS variation throughout the cow's lactation. Furthermore, BCS changes cannot be monitored at the cow level.

The objective of this study was to evaluate, using appropriate models, single lactation and daily measures of BCS level and BCS change throughout lactation as fertility indicator traits.

\section{MATERIALS AND METHODS}

\section{Data Description}

A data set with cow BCS records was obtained from Holstein UK. Edits removed records taken after d 305 of lactation, and cows that had their first calving outside the 18- to 40-mo age range. Further edits removed records in herd-year-seasons of visit (HYS) with size $<2$ and records of cows whose sires had $<2$ daughters. Three seasons of visit were defined as follows: January to April, May to August, and September to December (inclusive). The final data set consisted of 206,613 BCS cow records from 3934 sires distributed in 22,703 HYS. All cows were in their first lactation and had their first calving from 1996 through 2002. Figure 1 illustrates the distribution of records and BCS across the $305 \mathrm{~d}$ of lactation. On average, cows were visited and classified $132 \mathrm{~d}$ after they had calved.

The BCS data set was matched to datasets from National Milk Records and Cattle Information Service containing milk yield and fertility data. Fertility traits included calving interval (CI) between first and second calving and non-return rate (NR). The latter was re-

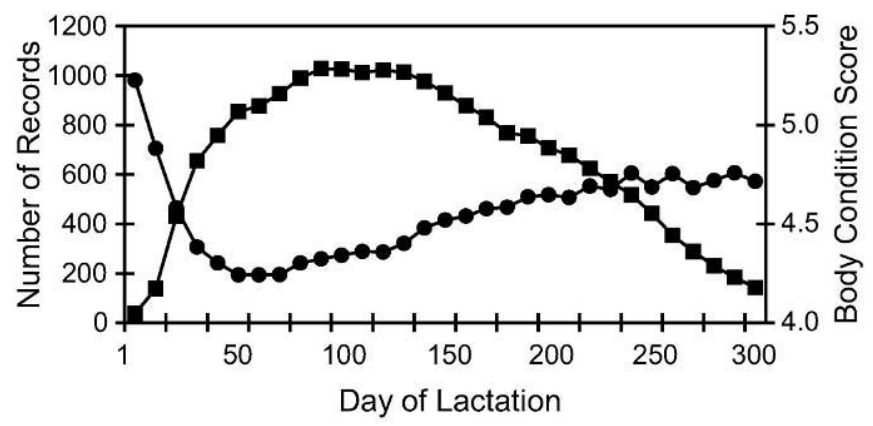

Figure 1. Distribution of number of records ( $\boldsymbol{\square})$ and body condition score () across day of lactation.

corded as 0 if the cow was re-inseminated $56 \mathrm{~d}$ after the first insemination and as 1 if the cow did not return to service in that period. Wall et al. (2003) described in detail the validation rules for insemination traits in the UK. These 2 fertility traits form the UK fertility index. Milk yield was daily yield at test nearest to d 110 of lactation (DMY), which was used in the preliminary genetic evaluation for fertility (Wall et al., 2003). All cows had BCS and DMY records, whereas 73 and $92 \%$, respectively, had CI and NR records. Table 1 summarizes the data used in this study.

\section{BCS Data Analyses}

Body condition score was analyzed as repeated measures per sire. This was possible given the distribution of sire daughter BCS throughout the lactation. Because there was only one observation per cow, a sire rather than animal model was used. Data were analyzed with the following random regression model:

$$
\begin{gathered}
\mathrm{y}_{\mathrm{hijkl}}=\mathrm{MC}_{\mathrm{k}}+\mathrm{b}_{\mathrm{p}} \cdot \mathrm{pch}+\mathrm{b} 1_{\mathrm{a}} \cdot \mathrm{AC}+\mathrm{b} 2_{\mathrm{a}} \\
\cdot \mathrm{AC}^{2}+\mathrm{mo}_{\mathrm{l}}+\mathrm{b}_{\mathrm{m}} \cdot \mathrm{DMY}+\mathrm{b}_{\mathrm{d}} \cdot \mathrm{days} \\
+\sum_{m=0}^{4} \beta_{\mathrm{jm}} \cdot \mathrm{d}_{\mathrm{jm}}+\sum_{m=0}^{3} \alpha_{\mathrm{im}} \cdot \mathrm{d}_{\mathrm{jm}}+\mathrm{e}_{\mathrm{hijkl}}
\end{gathered}
$$

where $y_{\text {hijkl }}=$ BCS of daughter $\mathrm{h}$ of sire $\mathrm{i}$ on day $\mathrm{j}$ of lactation in management class $\mathrm{k} ; \mathrm{MC}_{\mathrm{k}}=$ fixed effect of management class $\mathrm{k}$ defined as either HYS or the HYS

Table 1. Data description for BCS, calving interval (CI), non-return rate (NR), and daily milk yield at test nearest d 110 (DMY).

\begin{tabular}{llrr}
\hline Trait (unit) & Records (no.) & Mean & \multicolumn{1}{c}{ SD } \\
\hline BCS (score) & 206,613 & 4.47 & 1.57 \\
CI (d) & 150,301 & 396.39 & 55.22 \\
NR (0/1) & 190,407 & 0.67 & 0.47 \\
DMY (kg) & 206,613 & 25.77 & 5.81 \\
\hline
\end{tabular}


by day of lactation interaction (HYSd); $b_{p}=$ fixed linear regression on percentage North American Holstein genes $(\mathbf{p c h}) ; \mathrm{b} 1_{\mathrm{a}}$ and $\mathrm{b} 2_{\mathrm{a}}=$ fixed linear and quadratic regression on age at calving (AC), respectively; mo = fixed effect of month of calving $l ; b_{m}$ and $b_{d}=$ fixed linear regressions on DMY and corresponding days of lactation (days), respectively; $\mathrm{d}_{\mathrm{jm}}=$ Legendre polynomial $\mathrm{m}$ of BCS on day $\mathrm{j}$ of lactation, $\beta_{\mathrm{jm}}=$ fixed regression coefficient of BCS on day $\mathrm{j}$ of lactation, $\alpha_{\mathrm{im}}=$ random regression coefficient on sire $i$ with (co)variance matrix $\mathbf{A} \cdot \mathbf{G}(\mathbf{A}=$ sire relationship matrix $) ;$ and $\mathrm{e}_{\mathrm{hijkl}}=$ random residual with (co)variance matrix $\mathbf{R}$. Based on a previous study with similar data (Coffey et al., 2003), the order of the fixed and random regression polynomials was set to 5 (quartic including intercept) and 4 (cubic including intercept), respectively. Based on the study of Coffey et al. (2003), 10 measurement error classes were defined as follows: $d 1$ to 15,16 to 29,30 to 59 , 60 to 89,90 to 119,120 to 149,150 to 179,180 to 209, 210 to 239, and 240 to 305 of lactation. Different residual variances were estimated for each class. Residual co-variances were assumed to be zero. Variance components were estimated with the ASREML software package (Gilmour et al., 1998).

Sire variances of BCS on day $\mathrm{j}$ of lactation $\left(\mathrm{V}_{\mathrm{j}}\right)$ were estimated as $V_{j}=\mathbf{d}_{j}{ }^{\prime} \cdot \mathbf{G} \cdot \mathbf{d}_{j}$, where $\mathbf{d}_{\mathrm{j}}$ is the polynomial vector for day $\mathbf{j}$ and $\mathbf{G}$ is as defined in model [1]. Similarly, sire BCS co-variances between days $\mathrm{i}$ and $\mathrm{j}\left(\mathrm{COV}_{\mathrm{ij}}\right)$ were estimated as $\mathrm{COV}_{\mathrm{ij}}=\mathbf{d}_{\mathrm{i}}{ }^{\prime} \cdot \mathbf{G} \cdot \mathbf{d}_{\mathrm{j}}$. Sire variance of BCS change from day $i$ to $j$ was then estimated as the sum of individual day variances minus twice their covariance.

Prediction error variances per sire for day j of lactation $\left(\mathrm{PEV}_{\mathrm{j}}\right)$ were estimated as $\mathrm{PEV}_{\mathrm{j}}=\mathbf{d}_{\mathrm{j}}{ }^{\prime} \cdot \mathbf{S} \cdot \mathbf{d}_{\mathrm{j}}$, where $\mathbf{d}_{\mathrm{j}}$ is the polynomial vector for day $\mathrm{j}$ and $\mathbf{S}$ is the square of the diagonal standard error matrix for each sire solution. Sire reliability for day $\mathrm{j}$ was then calculated as [1 $\left.-\left(\mathrm{PEV}_{\mathrm{j}} / \mathrm{V}_{\mathrm{j}}\right)\right]$. Similarly, prediction error co-variances per sire between days $\mathrm{i}$ and $\mathrm{j}\left(\mathrm{PECOV}_{\mathrm{ij}}\right)$ were estimated as $\mathrm{PECOV}_{\mathrm{ij}}=\mathbf{d}_{\mathrm{i}}{ }^{\prime} \cdot \mathbf{S} \cdot \mathbf{d}_{\mathrm{j}}$. Prediction error variance of BCS change from day $i$ to $j$ was then estimated as the sum of individual day PEV minus twice PECOV, and reliability of BCS change was calculated from this and the corresponding sire variance.

Body condition score was also analyzed as a single lactation measure with single-trait model [2]:

$$
\begin{gathered}
\mathrm{y}_{\mathrm{hijkl}}=\mathrm{MC}_{\mathrm{k}}+\mathrm{b}_{\mathrm{p}} \cdot \mathrm{pch}+\mathrm{b1_{ \textrm {a } }} \cdot \mathrm{AC}+\mathrm{b} 2_{\mathrm{a}} \\
\cdot \mathrm{AC}^{2}+\mathrm{mo}_{\mathrm{l}}+\mathrm{b}_{\mathrm{m}} \cdot \mathrm{DMY}+\mathrm{b}_{\mathrm{d}} \cdot \text { days }+\mathrm{b}_{\mathrm{c}} \\
\cdot \mathrm{dcs}+\operatorname{sire}_{\mathrm{i}}+\mathrm{e}_{\mathrm{hijkl}}
\end{gathered}
$$

where $\mathrm{MC}_{\mathrm{k}}=$ fixed effect of HYS $\mathrm{k}, \mathrm{b}_{\mathrm{c}}=$ fixed linear regression on days of lactation when the cow was scored for body condition (dcs), and sire = random effect of sire i. All other effects were as defined in model [1].

\section{Correlation Between BCS and Fertility}

Sire evaluations for each day of lactation calculated with model [1] were used to estimate genetic correlations between daily BCS and fertility with bivariate analyses based on model [3]:

$$
\begin{gathered}
\mathrm{y} 1_{\text {hikl }}, \mathrm{y} 2_{\text {hikl }}=\mathrm{MC}_{\mathrm{k}}+\mathrm{b}_{\mathrm{p}} \cdot \mathrm{pch}+\mathrm{b} 1_{\mathrm{a}} \cdot \mathrm{AC} \\
+\mathrm{b} 2_{\mathrm{a}} \cdot \mathrm{AC}^{2}+\mathrm{mo}_{1}+\mathrm{b}_{\mathrm{m}} \cdot \mathrm{DMY}+ \\
\mathrm{b}_{\mathrm{B}} \cdot \mathrm{dBCS}+\mathrm{e}_{\text {hikl }}
\end{gathered}
$$

where $\mathrm{y} 1=\mathrm{DMY}$ and $\mathrm{y} 2=\mathrm{CI}$ or NR record of daughter $\mathrm{h}$ of sire $\mathrm{i}, \mathrm{MC}_{\mathrm{k}}=$ fixed effect of herd-year-season of calving $\mathrm{k}$, and $\mathrm{b}_{\mathrm{B}}=$ fixed linear regression on the daily sire genetic evaluation for BCS from model [1] weighted by its reliability (dBCS). Other effects were as in model [1]. The analysis was repeated 305 times, once for each day of lactation. Although we were interested in the genetic correlation between BCS and fertility traits, DMY was included to use all records available and account for selection bias. The genetic correlation between daily BCS and fertility traits was calculated by multiplying the estimated regression on daily BCS evaluation from model [3] with the ratio of genetic standard deviations of daily BCS over CI or NR. We chose this procedure because we wanted to estimate the genetic correlation between a trait analyzed as repeated measures (BCS) and traits analyzed as single measures (CI and NR). We were not convinced that our software would accommodate a multiple-trait (BCS and fertility) analysis in this context. Brotherstone and Hill (1991) and Pryce et al. (2000) followed a similar procedure to estimate correlations between herd life and type traits, and BCS and CI, respectively. The procedure may be sensitive to genetic variances assumed. In this case, genetic variances of daily BCS were those that had been estimated with model [1]. Genetic variances of fertility traits were estimated with model [4] shown subsequently. Standard errors of the genetic correlation estimates were calculated as the product of the point estimate times the square root of the sum of the ratios of the variance of the regression coefficient estimate over the estimate squared and the variances of the 2 genetic variance estimates over 4 times the respective estimates squared. This formula assumes no co-variances between the regression coefficient and the genetic variance estimates. 


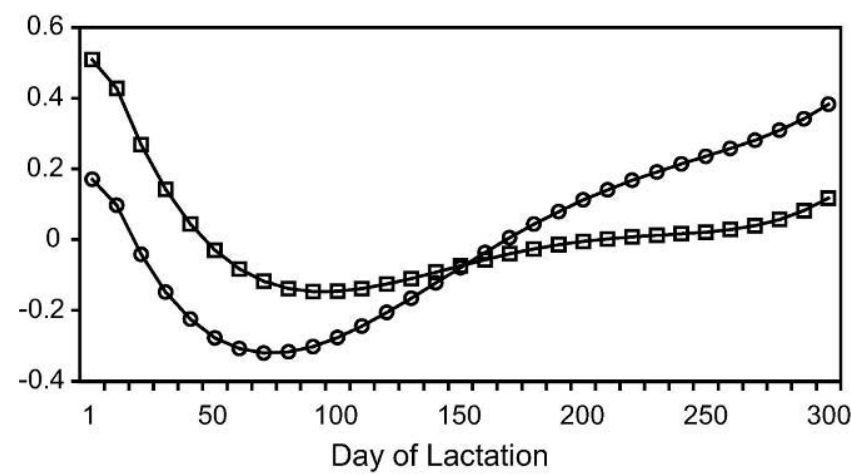

Figure 2. Fixed regression of BCS on day of lactation when the model includes a herd-year-season $(O)$ or herd-year-season by day of lactation interaction $(\square)$ management group.

$$
\begin{gathered}
\mathrm{y} 1_{\text {hikl }}, \mathrm{y} 2_{\text {hikl }}=\mathrm{MC}_{\mathrm{k}}+\mathrm{b}_{\mathrm{p}} \cdot \mathrm{pch}+\mathrm{b} 1_{\mathrm{a}} \cdot \mathrm{AC} \\
+\mathrm{b} 2_{\mathrm{a}} \cdot \mathrm{AC}^{2}+\mathrm{mo} \mathrm{o}_{1}+\mathrm{b}_{\mathrm{m}} \cdot \mathrm{DMY}+ \\
\mathrm{b}_{\mathrm{d}} \cdot \text { days }+\mathrm{b}_{\mathrm{c}} \cdot \mathrm{dcs}+\text { sire }_{\mathrm{i}}+\mathrm{e}_{\text {hikl }}
\end{gathered}
$$

where $\mathrm{y} 1=\mathrm{BCS}, \mathrm{y} 2=\mathrm{CI}$ or NR record of daughter $\mathrm{h}$ of sire $\mathrm{i}$, and $\mathrm{MC}_{\mathrm{k}}=$ fixed effect of herd-year-season of visit $\mathrm{k}$ (for BCS) or calving (for CI and NR). All other effects were as in model [2]. Genetic correlations between single measures of BCS and fertility traits were estimated with model [4].

The genetic correlation between fertility and BCS change from the beginning of the lactation was estimated by sequentially fitting in model [3] the difference of sire genetic evaluations on d 11 to 305 from the evaluation on $\mathrm{d} 10$, weighted by the corresponding reliability. Day 10 was considered as the reference day representing the beginning of lactation because earlier days were largely missing any validated BCS records. The exercise was repeated using sire genetic evaluation difference between d 30 and d 31 through 305 .

\section{RESULTS}

\section{BCS Data Analyses}

Fixed regression estimates of BCS on days of lactation are shown in Figure 2. For both management group models, BCS decreased during the first 2 to 3 mo of lactation and increased afterward. When the model included a HYS management group effect, BCS increase was greater than the initial drop. When HYSd defined the management group, BCS increased to lower levels than its initial value at the beginning of lactation. The latter is considered a more accurate description of the BCS curve. When the management group includes the stage of lactation (as HYSd does) it accounts for the physiological BCS change during the lactation (Figure

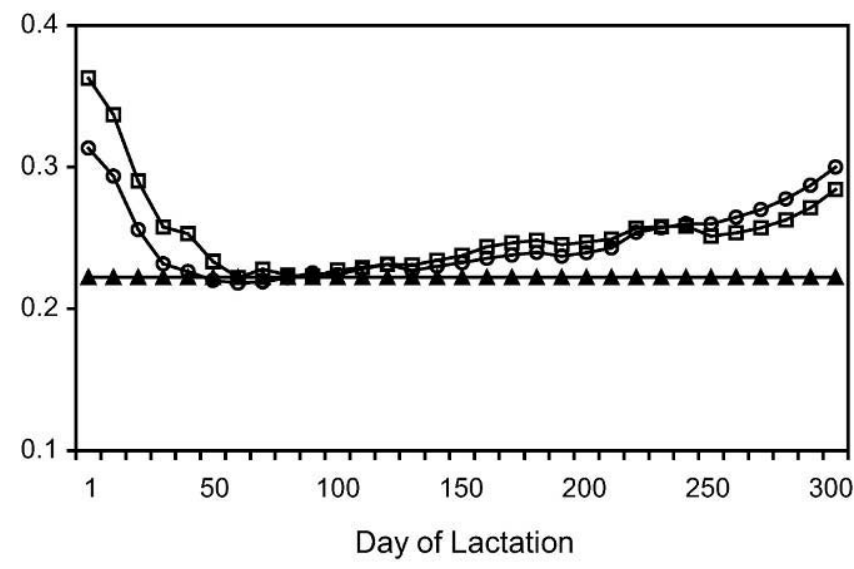

Figure 3. Heritability of single measure BCS ( $\mathbf{\Delta})$ and daily BCS from random regression analysis including a herd-year-season $(\bigcirc)$ or herd-year-season by day of lactation interaction ( $\square$ ) management group.

1). Otherwise, cows at a low energy stage (e.g., d 40 to 100 in lactation) would be unfavorably compared with their herdmates who are toward the end of their lactation and in the same contemporary group. Fitting a fixed regression on days in lactation only partially accounts for this. In addition, when the model includes HYS, fixed curves are allowed to vary among management groups by a constant. When a HYSd is fitted instead, fixed curves are also allowed to vary in slope, which goes some way to allowing all coefficients of the fixed regression in model [1] to vary depending on management group. Heritability of BCS estimated with models [1] and [2] is given in Figure 3. Single measure BCS heritability was tangential to the heritability curve estimated with random regression models. Daily heritability estimates were higher at either end of the curve as result of higher sire variance estimates in early and, less so, late lactation. Table 2 shows estimates of sire variance for selected days of lactation. Veerkamp et al. (2001) also reported changing genetic variance estimates throughout lactation from random regression model analysis. In their study, however, early lactation (d 1 to 50) genetic variance estimates were not higher than estimates in the remaining lactation. Small numbers of records at either end of the lactation period (Figure 1) may compromise the accuracy of these estimates. Nevertheless, in our study, daily sire variance estimates at various stages of lactation differed significantly from each other (Table 2).

Average sire reliabilities per day of lactation estimated with model [1] ranged from 0.27 in the beginning (d 1 to 50$)$ and end (d >250) of the lactation to 0.48 in the middle ( $\mathrm{d} 100$ to 180) of the lactation. Higher estimates in midlactation were consistent with a heav- 
Table 2. Sire variance estimates for daily BCS (selected days) from random regression analysis including a herd-year-season (HYS) or herd-year-season by days of lactation interaction (HYSd) management group and corresponding regressions of calving interval (CI) and non-return rate (NR) on daily BCS.

\begin{tabular}{|c|c|c|c|c|c|c|}
\hline \multirow{2}{*}{$\begin{array}{l}\text { Day of } \\
\text { lactation }\end{array}$} & \multicolumn{2}{|c|}{ Variance estimate $^{1}$} & \multicolumn{2}{|c|}{ CI Regression ${ }^{2}$} & \multicolumn{2}{|c|}{ NR Regression ${ }^{3}$} \\
\hline & HYS & HYSd & HYS & HYSd & HYS & HYSd \\
\hline 10 & 0.132 & 0.195 & -4.19 & -3.54 & -0.017 & -0.012 \\
\hline 70 & 0.103 & 0.114 & -4.79 & -4.82 & -0.014 & -0.012 \\
\hline 150 & 0.117 & 0.122 & -4.27 & -4.40 & -0.012 & -0.011 \\
\hline 280 & 0.143 & 0.139 & -3.64 & -4.15 & -0.012 & -0.011 \\
\hline
\end{tabular}

${ }^{1} \mathrm{SE}=0.006$ to 0.018 .

${ }^{2} \mathrm{SE}=0.40$ to 0.80 ; CI sire variance, $20.0 \pm 2.8$.

${ }^{3} \mathrm{SE}=0.005$ to $0.007 ; \mathrm{NR}$ sire variance, $0.00044 \pm 0.0001$.

ier concentration of cow records during this period (Figure 1). Single measure reliability estimated with model [2] averaged 0.51 for all bulls.

Genetic correlations among daily BCS records were near unity for adjacent days or days close to each other and decreased as the distance between days increased. Genetic correlations of BCS in early lactation (d 1 to 50 ) were 0.70 to 0.75 with midlactation (d 100 to 180 ) $\mathrm{BCS}$, and were 0.50 to 0.60 with late $(\mathrm{d}>250)$ lactation BCS. Genetic correlations between mid and late lactation BCS ranged from 0.81 to 0.96 . These results suggest that the trait changes genetically as lactation progresses.

\section{Correlation Between BCS and Fertility}

Genetic correlations between daily BCS and CI estimated with model [3] and between single measure BCS and CI from model [4] are shown in Figure 4. Genetic correlations ranged from -0.35 to -0.31 ( $\mathrm{SE}=0.06$ to 0.07 ) with the HYS model and from -0.37 to -0.34 ( $\mathrm{SE}=$ 0.06 to 0.07 ) with the HYSd model. Correlations were

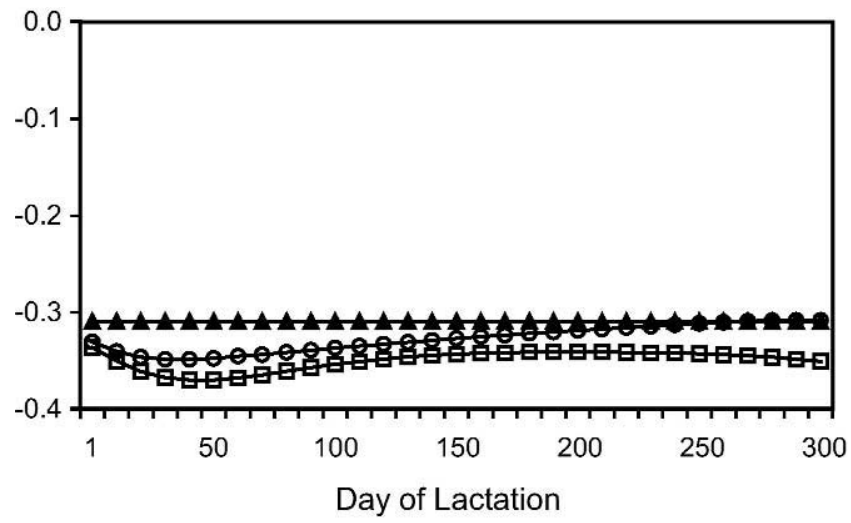

Figure 4. Genetic correlation of calving interval with single measure BCS $(\mathbf{\Delta})$ and daily BCS from random regression analysis including a herd-year-season $(\bigcirc)$ or herd-year-season by day of lactation interaction $(\square)$ management group; $\mathrm{SE}=0.06$ to 0.07 . strongest at around d 50 to 70 of the lactation and weakest toward the end, consistent with the size of the corresponding regression coefficients (see Table 2 for selected estimates). However, the standard errors of these estimates suggest that differences were not significant. Correlation estimates of daily BCS were slightly higher than the single measure BCS estimate of -0.31 ( $\mathrm{SE}=0.07)$, but differences were not significant.

Genetic correlations between change of daily BCS from d 10 and CI estimated with model [3] (not shown) ranged from 0.07 to 0.14 ( $\mathrm{SE}=0.08$ to 0.09 ) with the HYS model and from 0.05 to 0.08 ( $\mathrm{SE}=0.07$ to 0.08 ) with the HYSd model. Estimates slightly increased with progressing lactation, but their large standard errors render them non-significantly different from zero. When daily BCS change from d 30 was considered instead of d 10, results (not shown) were practically the same.

Genetic correlations between daily BCS and NR estimated with model [3] and between single measure BCS and NR from model [4] are shown in Figure 5. Genetic correlations ranged from -0.32 to -0.19 ( $\mathrm{SE}=0.08$ to

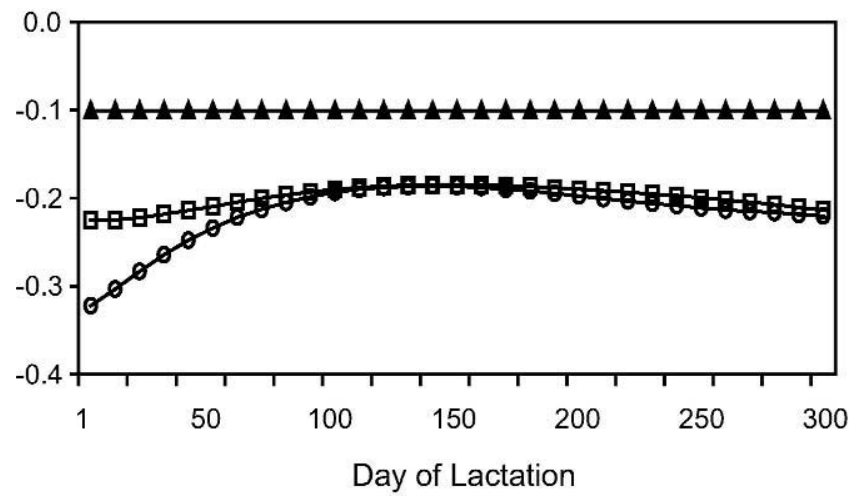

Figure 5. Genetic correlation of non-return rate with single measure BCS $(\boldsymbol{\Delta})$ and daily BCS from random regression analysis including a herd-year-season $(\bigcirc)$ or herd-year-season by day of lactation interaction $(\square)$ management group; $\mathrm{SE}=0.08$ to 0.11 . 


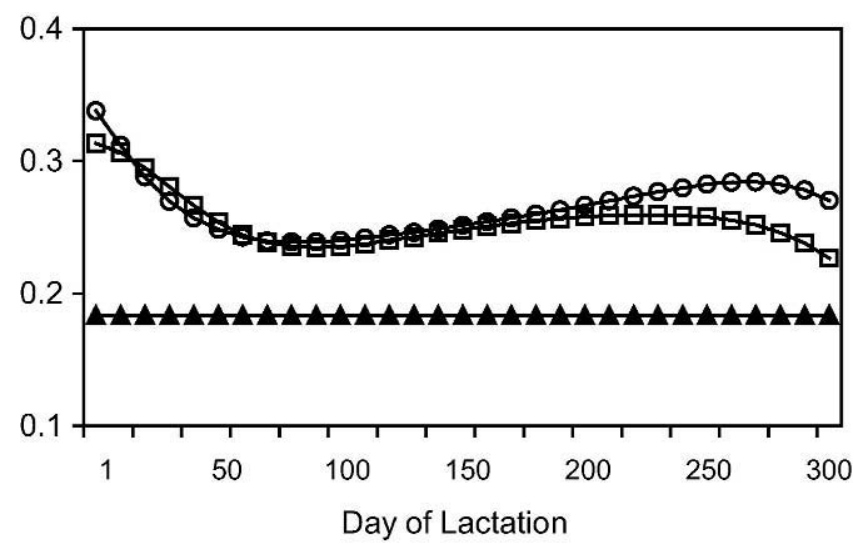

Figure 6. Product of the genetic correlation between fertility index and single measure BCS ( $(\mathbf{\Delta})$ and daily BCS from random regression analysis including a herd-year-season $(\bigcirc)$ or herd-year-season by day of lactation interaction $(\square)$ management group times the corresponding accuracy of the BCS evaluation.

0.11 ) with the HYS model and from -0.22 to -0.19 ( $\mathrm{SE}=$ 0.08 to 0.11 ) with the HYSd model. Correlations were strongest at the beginning of the lactation with a gradual decrease toward the end, especially when the HYS model was used, consistent with the size of the corresponding regression coefficients (see Table 2 for selected estimates). Correlation estimates with NR were consistently higher for daily BCS than for the single measure BCS estimate of -0.11 ( $\mathrm{SE}=0.08)$, but differences were not always significant.

Genetic correlations between daily BCS change from d 10 and NR estimated with model [3] (not shown) ranged from -0.21 to -0.05 ( $\mathrm{SE}=0.13$ to 0.15 ) with the HYS model and from -0.08 to 0.00 ( $\mathrm{SE}=0.12$ to 0.14 ) with the HYSd model. Estimates approached zero with progressing lactation, but their large standard errors render them all non-significantly different from zero. The same results (not shown) were obtained when daily BCS change from d 30 was considered instead of $d 10$.

Genetic correlations of various BCS measures with fertility determine their predictive capacity only to the extent that BCS reliability remains constant. This, however, was not the case in this study. Therefore, the value of each daily BCS evaluation as a fertility indicator trait was assessed by multiplying its genetic correlation with fertility with the square root of its reliability, as illustrated in Figure 6. Results shown in Figure 6 pertain to the UK fertility index, which is based on genetic evaluations for CI and NR, placing approximately 1:5 weights on the 2 traits. This is conceptually the variable part of correlated response in fertility from selecting on various BCS measures. For comparison, Figure 6 includes the product of single measure BCS square root reliability from model [2] times its genetic correlation with fertility from model [4]. In this respect, daily BCS measures from random regression model analysis either with HYS or HYSd constantly out-performed single measure BCS by 28 to $53 \%$.

\section{DISCUSSION}

A constant body condition score is associated with the ability of the cow to produce milk while maintaining its energy balance. Because of changes in daily milk yield throughout the lactation and other physiological changes, including reproduction and pregnancy status, the energy balance profile varies, prompting variation of daily BCS (Coffey et al., 2003). In fact, Coffey et al. (2003) found that the lowest body energy level occurs, on average, 3 mo postpartum, very close to the peak of daily milk yield. In the present study, the fixed regression of BCS on days of lactation was lowest on $\mathrm{d} 72$ and 87 for HYS and HYSd models, respectively, reflecting the lowest body energy levels. Because the HYSd model allows for better comparisons both within and between management groups, the value of 87 is accepted as the more correct of the 2 , suggesting that the lowest adjusted phenotypic BCS is expected to occur on this day, very close to the energy balance nadir suggested by Coffey et al. (2003).

The changing genetic profile of BCS throughout the lactation, observed in this study, was illustrated by the heritability curve and genetic correlation estimates below unity among different daily BCS. Results were, in general, consistent with previous studies (Jones et al., 1999; Berry et al., 2002) and suggest that BCS is not genetically the same trait in various stages of lactation. This is not surprising given the BCS association with energy balance. The daily BCS variation was harnessed using random regression models, and distinct genetic parameters were estimated for each daily measure.

The relationship of energy balance with reproduction and fertility has been documented in the literature (Collard et al., 2000; de Vries and Veerkamp, 2000; Veerkamp et al., 2000). Negative energy balance is associated with difficulties for the cow to conceive and maintain the calf. Unfortunately, body energy is at its lowest when inseminations have usually just started, often leading to fertility problems particularly in high-yielding cows. Therefore, BCS measured at that time might have been expected to give better than average information on cow fertility. Results of this study partially corroborate this claim. Genetic correlations between BCS and either CI or NR were consistently higher for daily than for single lactation measure of BCS. Differences, however, were mostly nonsignificant. Genetic correla- 
tions were strongest at the early stages of lactation, suggesting that early daily BCS measures are probably better predictors of fertility. This is related to the animal genetic component being more pronounced at early stages of lactation, as suggested by higher heritability and sire variance estimates from a random regression model. Strong regressions of cow fertility on genetic merit of sires for BCS in early lactation further support the claim. These results are in partial agreement, at least regarding the relative strength of the correlation estimate, with Veerkamp et al. (2001) and Berry et al. (2003). In our study, both HYS and HYSd models yielded similar estimates, suggesting that the definition of management group is not expected to affect the predictive power of daily BCS.

Looking for the best genetic indicator of a trait is conceptually equivalent to selecting for the predictor to elicit a correlated response in the trait of interest. In this case, BCS is the predictor, and fertility is the trait we wish to improve genetically. The correlated response then becomes a function of the genetic correlation between BCS and fertility and the accuracy (square root of the reliability) of the BCS genetic evaluation. Fertility in the UK is considered as the combination of CI and NR, with approximate weights of $1: 5$ on the 2 traits. These weights were placed on the product of genetic correlation between BCS and CI or NR and accuracy of BCS evaluation and compared for the various BCS measures. When BCS was analyzed as a repeated measure with random regressions, its predictive capacity was increased by 28 to $53 \%$ compared with single measure BCS analysis. The improvement was more pronounced at early stages of lactation and stabilized after $\mathrm{d} 75$. The observed superiority of the random regression over single measure analysis results is attributed to NR, which is the dominant trait in the fertility index. Analyzing BCS with random regression models, compared with single measure analysis, improved the genetic correlation with NR more than with CI.

The change in BCS evaluation across lactation did not have high genetic correlation with fertility traits. In all cases, genetic correlation estimates were considerably lower than estimates for BCS level, supporting earlier reports by Pryce et al. (2001) and Berry et al. (2003). A possible explanation may be that each cow has a genetically predetermined lowest level of body energy (and BCS) that she is allowed to reach, and it is this nadir that determines her aptitude for fertility. The speed of reaching this level seems to be less important than the level itself. Results of this study suggest that BCS change across lactation is not as useful as BCS level for predicting fertility.

\section{CONCLUSIONS}

Based on the results of this study, BCS analyzed either as repeated or single measures can be used as a predictor of fertility. Correlations between fertility and BCS changes across lactation were not significantly different from zero. Daily BCS parameters derived from random regression analyses suggested that measures obtained in the first stage (about d 75) of lactation are the best predictors. This is primarily because of the stronger genetic correlation with NR and the relatively large weight the current UK fertility index places on this trait. Analysis of field-recorded BCS as repeated measures per sire using the HYSd model would be preferable because it captures the variation of the trait across lactation. Improving the consistency of BCS recording in the first 3 mo of lactation would facilitate its use as a predictor of fertility.

\section{ACKNOWLEDGMENTS}

The authors acknowledge the funding and support of the UK Department for Environment, Food and Rural Affairs (LINK Sustainable Livestock Production Program), National Milk Records plc., Cattle Information Services (UK) Ltd., Genus Breeding Ltd., Cogent Breeding Ltd., Holstein UK, and Dartington Cattle Breeding Trust.

\section{REFERENCES}

Berry, D. P., F. Buckley, P. Dillon, R. D. Evans, M. Rath, and R. F. Veerkamp. 2002. Genetic parameters for level and change of body condition score and body weight in dairy cows. J. Dairy Sci. 85:2030-2039.

Berry, D. P., F. Buckley, P. Dillon, R. D. Evans, M. Rath, and R. F. Veerkamp. 2003. Genetic relationships among body condition score, body weight, milk yield and fertility in dairy cows. J. Dairy Sci. 86:21932204.

Brotherstone, S. 1994. Genetic and phenotypic correlations between linear type traits and production traits in Holstein-Friesian dairy cattle. Anim. Prod. 59:183-187.

Brotherstone, S., and W. G. Hill. 1991. Dairy herd life in relation to linear type traits and production 1. Phenotypic and genetic analyses in pedigree type classified herds. Anim. Prod. 53:279287.

Coffey, M. P., G. Simm, and S. Brotherstone. 2002. Energy balance profiles for the first three lactations of dairy cows estimated using random regression. J. Dairy Sci. 85:2669-2678.

Coffey, M. P., G. Simm, W. G. Hill, and S. Brotherstone. 2003. Genetic evaluations of dairy bulls for daughter energy balance profiles using linear type scores and body condition score analyzed using random regressions. J. Dairy Sci. 86:2205-2212.

Collard, B. L., P. J. Boettcher, J. C. M. Dekkers, D. Petitclerc, and L. R. Schaeffer. 2000. Relationships between energy balance and health traits of dairy cattle in early lactation. J. Dairy Sci. 83:2683-2690.

Dechow, C. D., G. W. Rogers, and J. S. Clay. 2001. Heritabilities and correlations among body condition scores, production traits, and reproductive performance. J. Dairy Sci. 84:266-275.

de Vries, M. J., and R. F. Veerkamp. 2000. Energy balance of dairy cattle in relation to milk production variables and fertility. J. Dairy Sci. 83:62-69. 
Gilmour, A. R., B. R. Cullis, S. J. Welham, and R. Thompson. 1998. ASREML User's Manual. New South Wales Agriculture, Orange Agricultural Institute, Orange, NSW, Australia.

Harrison, R. O., S. P. Ford, J. W. Young, and A. J. Conley. 1990. Increased milk production versus reproductive and energy status of high producing dairy cows. J. Dairy Sci. 73:2749-2758.

Jones, H. E., I. M. S. White, and S. Brotherstone. 1999. Genetic evaluation of Holstein Friesian sires for daughter condition score changes using a random regression model. Anim. Sci. 68:467-476.

Kadarmideen, H. N., and M. P. Coffey. 2001. Quality and validation of insemination data for national genetic evaluations for dairy cow fertility in the United Kingdom. Proc. Interbull Mtg., Budapest, Hungary, August 2001. Interbull Bull. No. 27:133-138.

Pryce, J. E., and R. F. Veerkamp. 2001. The incorporation of fertility indices in genetic improvement programmes. Pages 223-236 in Fertility in the High-Producing Dairy Cow. M. G. Diskin, ed. Br. Soc. Anim. Sci. Occ. Publ. No. 26. Edinburgh, Scotland.

Pryce, J. E., M. P. Coffey, and S. Brotherstone. 2000. The genetic relationship between calving interval, body condition score and linear type and management traits in registered Holsteins. J. Dairy Sci. 83:2664-2671.

Pryce, J. E., M. P. Coffey, and G. Simm. 2001. The relationship between body condition score and reproductive performance. J. Dairy Sci. 84:1508-1515.
Pryce, J. E., R. J. Esslemont, R. Thompson, R. F. Veerkamp, M. A. Kossaibati, and G. Simm. 1998. Estimation of genetic parameters using health, fertility and production data from a management recording system for dairy cattle. Anim. Sci. 66:577-584.

Roxström, A., E. Strandberg, B. Berglund, U. Emanuelson, and J. Philipsson. 2001. Genetic and environmental correlations among the female fertility traits, and between the ability to show oestrus and milk production in dairy cattle. Acta Agric. Scand., Sect. A. Anim. Sci. 51:192-199.

Royal, M. D., A. O. Darwash, A. P. F. Flint, R. Webb, J. A. Woolliams, and G. E. Lamming. 2000. Declining fertility in dairy cattle: Changes in traditional and endocrine parameters of fertility. Anim. Sci. 70:487-501.

Veerkamp, R. F., J. K. Oldenbroek, H. J. Van Der Gaast, and J. H. J. Van Der Werf. 2000. Genetic correlation between days until start of luteal activity and milk yield, energy balance, and live weights. J. Dairy Sci. 83:577-583.

Veerkamp, R. F., E. P. C. Koenen, and G. de Jong. 2001. Genetic correlations among body condition score, yield, and fertility in first-parity cows estimated by random regression models. J. Dairy Sci. 84:2327-2335.

Wall, E., S. Brotherstone, J. A. Woolliams, G. Banos, and M. P. Coffey. 2003. Genetic evaluation of fertility using direct and correlated traits. J. Dairy Sci. 86:4093-4102. 